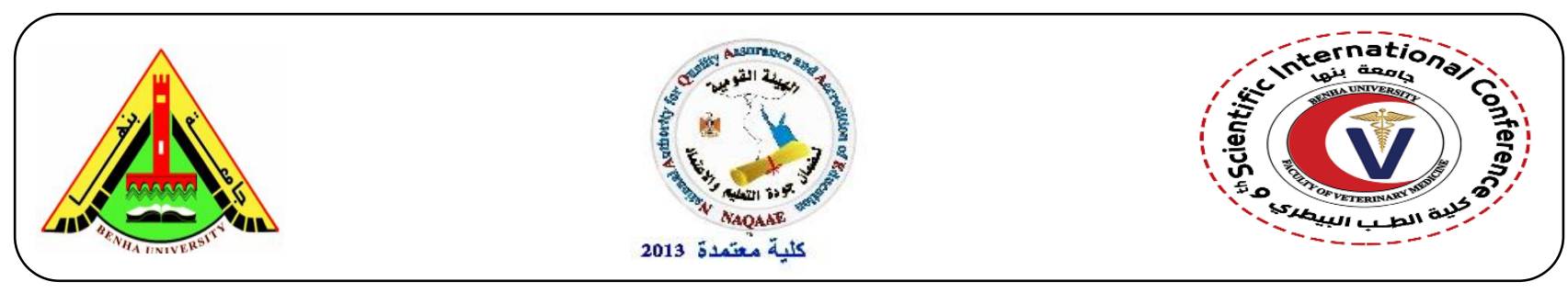

\title{
Lycopene and its Potential Role in Diabetic Nephropathy Induced in Rats
}

\author{
Samy A. Hussein*; Mohamed R.R. Hassanein and Maher A. Awadalla \\ Department of Biochemistry, Faculty of Vet. Med., Benha University, Egypt. \\ *Corresponding author: Samy Ali Hussein; email: samyaziza@yahoo.com
}

\section{A B S T R A C T}

Diabetic nephropathy (DN) is an important microvascular complication of diabetes and one of the main causes of end stage renal disease. The protective effect of lycopene against streptozotocin (STZ) induced diabetic nephropathy and oxidative stress in rats was evaluated. Seventy two male albino rats were divided into four groups. Group I (normal group): rats administered buffer citrate. Group II (DN group): rats received a single intraperitoneal (i.p) injected dose of STZ (50 mg/kg b.wt). Group III (DN + insulin treated group): diabetic nephropathy rats treated with insulin (2U/rat/day/i.p). Group IV (DN + lycopene treated group): diabetic nephropathy rats treated with lycopene $(20 \mathrm{mg} / \mathrm{kg}$ b.wt/day/orally). The obtained results showed a significant increase in serum glucose, urea, creatinine and kidney tissue L-MDA concentrations with upregulation of NF-kB gene expression in diabetic nephropathy induced rats. However, SOD activity and GSH level of kidney tissues were markedly decreased. Administration of lycopene to DN induced rats caused a significant improvement of all previous parameters towards their normal range. These results suggested that, lycopene treatment may have a protective effect against STZinduced diabetic nephropathy and oxidative stress in rats through free radical scavenging and antiinflammatory activity as well as regenerating endogenous antioxidant defense system mechanisms.

Key words: Streptozotocin, lycopene, oxidative stress, diabetic nephropathy.

\section{INTRODUCTION}

Diabetes mellitus is a group of metabolic alterations characterized by hyperglycemia resulting from defects in insulin secretion, action or both. Chronic hyperglycemia of diabetes is associated with long-term damage, dysfunction and eventually the failure of organs especially the 
eyes, nerves, heart, blood vessels and kidneys (Huang et al., 2005). Type II diabetes mellitus developed by metabolic abnormalities such as impaired insulin secretion, increased hepatic glucose production and decreased insulinstimulate of glucose uptake in peripheral tissues (Kakadiya et al., 2010).

Diabetes is usually accompanied by an increased production of reactive oxygen species (ROS) and free radicals or by impaired antioxidant defenses which are widely accepted as important in the development and progression of diabetic complications (Kumar et al., 2006). The increased risk of complications occurred particularly in subjects with poor glycaemic control (Gavin et al., 1997). In addition, diabetes causes increased oxidative stress in various tissues as evidenced by increased levels of oxidized DNA, proteins and lipids which are thought to play an important role in the pathogenesis of various diabetic complications (Chung et al., 2003). In diabetic patients with vascular complications, there are significant changes such as increased lipid peroxidation, dyslipidemia and irregularities in the metabolism of proteins, carbohydrates and lipids. Increased lipid peroxidation is accepted to be one of the main causes of diabetic complications (Gallou et al., 1994).

Diabetic nephropathy (DN) is a leading cause of end-stage renal failure worldwide. Its morphological characteristics include glomerular hypertrophy, basement membrane thickening, mesangial expansion, tubular atrophy, interstitial fibrosis and arteriolar thickening. All of these are part and parcel of microvascular complications of diabetes. A large body of evidence indicates that oxidative stress is the common valuable link for the major pathways involved in the development and progression of diabetic microvascular as well as macrovascular complications of diabetes. Several lines of evidence suggest the central role of oxidative stress in the development of DN and the beneficial effects of antioxidants in renal injury owing to diabetes (Bagchi and Puri, 1998).Traditionally, DN has been described as a glomerular disease with five different stages are glomerular hyperfiltration, incipient nephropathy, microalbuminuria, overt proteinuria and end-stage renal disease (Mogensen et al., 1983).

STZ is a glucosamine-nitrosouria compound that causes damage and destruction of $\beta$-cells primarily through nitric oxide mediated DNA damage. It enters $\beta$-cells via the reduced glucose transporter type 2 (GLUT-2 transporter) to which it binds readily due to its similarity in structure to glucose (Kaneto et al., 1995). STZ is toxic to the insulin producing beta cells of the Islets of Langerhans in the pancreas so it is widely employed to induce experimental diabetes in animals. It damages the DNA of pancreatic- $\beta$ cells and triggers multiple pathways including activation of protein kinase-C, poly (ADPribose) polymerase and $\mathrm{NAD}(\mathrm{P}) \mathrm{H}$ oxidase with consequent generation of ROS and advanced glycation end products resulting in renal damage and nephropathy (Haidara et al., 2008).

Antioxidants form a diverse group of compounds with different properties which operate by inhibiting oxidant formation, intercepting oxidants and repairing oxidant induced injuries (Ergüder et al., 2007). Tomato products contains lycopene which is believed to be associated with decreased risk of chronic diseases and its effects are suggested to be due to antioxidant effect of lycopene (Jamshidzadeh et al., 2008). The antioxidant properties of lycopene have been demonstrated both in vivo and in vitro (Wertz et al., 2004). There is also recent evidence suggests that lycopene acts as an anti- 
inflammatory agent (Kim et al., 2004). Lycopene can inhibit the expression of inflammatory cytokines and reverse the loss of antioxidant enzymes induced by inflammation caused by either injecting lipopolysaccharide or exposure to iron (Riso et al., 2006).This study was to investigate the possible beneficial effect of lycopene against deleterious effect of diabetic nephropathy induced in male rats through investigation of blood glucose, kidney functions, inflammatory and oxidative stress biomarkers.

\section{MATERIALS AND METHODS}

\subsection{Experimental animals:}

Seventy two white male albino rats of 5-6 weeks old and weighing 180 - $200 \mathrm{~g}$ were used in this study. Rats were housed in separated metal cages and kept at constant environmental and nutritional conditions throughout the period of experiment. The rats were fed on constant ration and fresh, clean drinking water was supplied ad-libitum. All rats were acclimatized for minimum period of 15 days prior to the beginning of study.

\subsection{Chemicals and antioxidant:}

All chemicals were of analytical grade and obtained from standard commercial suppliers .The antioxidant and chemicals used in the present study were:

a- Streptozotocin: STZ [2-deoxy-2-(3methyl-3-nitrosoureido)-D-glucopyranose], was purchased from (Sigma Chemical Co. P.O. Box. 14508, St. Lowis, U.S.A.). Freshly dissolved in citrate buffer, PH 4.5and administered intraperitoneally as a single injected dose of (50 mg $/ \mathrm{kg}$ body wt.) (Ramanathan et al., 1999).

b- Lycopene: lycopene was purchased from Aktin Chemicals, Inc. company (Nature connecting health), Chengdu, China, it was mixed in Tween-80 and saline is added till reach the final required concentration and administred orally to rats at a dose level of
(20 mg/kg b.wt) once daily for 6 weeks (Abdel-Azeem et al., 2013).

c- Other chemicals used in this study were of the highest purified grades available purchased from El Gomhouria Company for Trading Chemicals and Medical Appliances, Egypt.

\subsection{Experimental design:}

After acclimatization to the laboratory conditions, the animals were randomly divided into four groups placed in individual cages and classified as following:

Group I (normal control group): Consists of 12 rats, received no drugs, served as control non-treated for all experimental groups.

Group II (DN induced group): Consists of 24 rats, received STZ as a single intraperitoneally injected dose of $(50 \mathrm{mg} / \mathrm{kg}$ b.wt).

Group III (DN + insulin treated group): Consists of 18 rats, received STZ and after 8 weeks treated daily with insulin (2U/rat per day/i.p) for 6 weeks.

Group IV (DN + lycopene treated group): Consists of 18 rats, received STZ and after 8 weeks treated daily with lycopene $(20 \mathrm{mg} / \mathrm{kg}$ b.wt/ orally) for 6 weeks.

\subsection{Sampling:}

\subsubsection{Blood samples:}

Blood samples were collected by ocular vein puncture from all animal groups, at the end of experiment, after 14 weeks in dry clean tubes and allowed to clot for 30 minutes and serum was separated by centrifugation at 3000 r.p.m for 15 minute. The serum was taken by automatic pippte and received in dry sterile tubes and used directly for determination of blood glucose, urea and creatinine concentrations according to the method described by Tietz, (1995), Tietz, (1990) and Tietz, (1986). 


\subsubsection{Tissue samples:}

About $0.5 \mathrm{~g}$ of kidney tissue specimen was taken from all animal groups (control and experimental groups) once after the end of 14 weeks.

\subsection{Biochemical analysis}

\subsubsection{Kidney tissue for biochemical analysis}

Briefly, kidney tissues were cut, weighed and minced into small pieces, homogenized with a glass homogenizer in 9 volume of ice-cold $0.05 \mathrm{mM}$ potassium phosphate buffer ( $\mathrm{pH}$ 7.4) to make $10 \%$ homogenates. The homogenates were centrifuged at 6000 r.p.m for 15 minutes at $4^{\circ} \mathrm{C}$ then the resultant supernatant was used for the determination of the following parameters: SOD, GSH and L-MDA according to the method described by Kakkar et al., (1984), Paglia and Valentine, (1967) and (Mesbah et al., 2004) respectively.

\subsubsection{Kidney tissue for molecular analysis}

About 0.5 of kidney tissue put in eppendorf tubes and were immediately kept in liquid nitrogen and stored at $-80^{\circ} \mathrm{C}$ till RNA extraction for determination of NF-kB gene expression by real-time quantitative polymerase chain reaction (real- time qPCR) analysis in kidney of rats. Target gene was was normalized with $\beta$-actin by used the $2^{-}$ ${ }^{\Delta \Delta \mathrm{Ct}}$ method (Livak and Schmittgen, 2001).

Forward and reverse primers sequence for real time PCR.

\begin{tabular}{|l|l|c|}
\hline Gene & \multicolumn{1}{|c|}{$\begin{array}{c}\text { Forward primer } \\
(15-----/ 3)\end{array}$} & $\begin{array}{c}\text { Reverse primer } \\
(15----/ 3)\end{array}$ \\
\hline$N K-k B$ & CCTAGCTTTCTCTGACTGCAAA & GGGTCAGAGGCAATAGAGA \\
\hline$\beta$-actin & ACCCACACTGTGCCCATCTA & CGTCACACTTCATGATG \\
\hline
\end{tabular}

\subsection{Statistical analysis:}

The results were expressed as mean \pm SE using SPSS (13.0 software, 2009) program. The data were analyzed using oneway ANOVA to determine the statistical significance of differences among groups. Duncan's test was used for making a multiple comparisons among the groups for testing the inter-grouping homogeneity. Values were considered statistically significant when $\mathrm{p}<0.05$.

\section{RESULTS:}

The obtained data presented in table (1) revealed that, STZ-induced diabetic nephropathy rats showed a significant increase in serum glucose, urea and creatinine concentrations compared to normal control group.
Lycopene treatment to STZ-induced diabetic nephropathy rats caused a significant decrease in elevated serum glucose, urea and creatinine concentrations when compared with STZ-induced diabetic nephropathy group.

The obtained data presented in table (2) revealed that, STZ-induced diabetic nephropathy rats showed a significant increase in kidney tissue L-MDA with significant upregulation of NF-kB and significant decrease in SOD activity and GSH level compared to normal control group.

Lycopene treatment to STZ-induced diabetic nephropathy rats caused a significant decrease in kidney tissue L-MDA with a significant downregulation of NF-kB and a significant increase in SOD activity and GSH 
level compared to STZ-induced diabetic

nephropathy group.

Table (1): Effect of lycopene administration on serum glucose, urea and creatinine concentrations in streptozotocin induced diabetic nephropathy rats $(\mathrm{mg} / \mathrm{dl})$.

\begin{tabular}{lccc}
\hline Parameters & Glucose $(\mathrm{mg} / \mathrm{dl})$ & Urea $(\mathrm{mg} / \mathrm{dl})$ & Creatinine $(\mathrm{mg} / \mathrm{dl})$ \\
& & & \\
Exp. Groups & & $26.15 \pm 0.86^{\mathrm{d}}$ & $0.91 \pm 0.01^{\mathrm{d}}$ \\
\hline $\begin{array}{l}\text { Group I: } \\
\text { Normal control }\end{array}$ & $93.33 \pm 4.03^{\mathrm{e}}$ & $46.18 \pm 1.49^{\mathrm{a}}$ & $1.6 \pm 0.03^{\mathrm{a}}$ \\
$\begin{array}{l}\text { Group } \Pi \text { : } \\
\text { Control DN group }\end{array}$ & & & \\
Group III: & $159.33 \pm 5.19^{\mathrm{d}}$ & $29.47 \pm 0.94^{\mathrm{c}}$ & $0.98 \pm 0.03^{\mathrm{c}}$ \\
$\begin{array}{l}\text { DN + Insulin } \\
\text { Group IV: }\end{array}$ & $243.4 \pm 7.32^{\mathrm{b}}$ & $37.12 \pm 1.08^{\mathrm{b}}$ & $1.33 \pm 0.03^{\mathrm{b}}$ \\
DN+ Lycopene & & &
\end{tabular}

Data are presented as (Mean \pm S.E). $\quad$ S.E $=$ Standard error.

Mean values with different superscript letters in the same column are significantly different at $(\mathrm{P} \leq 0.05)$.

Table (2): Effect of lycopene administration on kidney tissue SOD, GSH, L-MDA and NF-kB levels in streptozotocin induced diabetic nephropathy rats.

\begin{tabular}{|c|c|c|c|c|}
\hline Exp. Groups & $\begin{array}{c}\text { SOD } \\
\text { (IU/g tissue) }\end{array}$ & $\begin{array}{c}\text { GSH } \\
\text { (IU/g tissue) }\end{array}$ & $\begin{array}{c}\text { L-MDA } \\
\text { nmol/g tissue }\end{array}$ & $\begin{array}{c}\text { Fold change in } \\
\text { NF-kB gene } \\
\text { expression }\end{array}$ \\
\hline $\begin{array}{l}\text { Group I: } \\
\text { Normal control }\end{array}$ & $0.96 \pm 0.04^{\mathrm{a}}$ & $20.00 \pm 0.95^{\mathrm{a}}$ & $38.67 \pm 1.28^{\mathrm{e}}$ & $1.00 \pm 0.01^{\mathrm{e}}$ \\
\hline $\begin{array}{l}\text { Group } \Pi \text { : } \\
\text { Control DN } \\
\text { group }\end{array}$ & $0.18 \pm 0.01^{\mathrm{e}}$ & $5.40 \pm 0.78^{d}$ & $95.80 \pm 3.42^{\mathrm{a}}$ & $10.06 \pm 0.35^{\mathrm{a}}$ \\
\hline $\begin{array}{l}\text { Group III: } \\
\text { DN+ Insulin }\end{array}$ & $0.78 \pm 0.03^{\mathrm{b}}$ & $15.20 \pm 0.70^{\mathrm{b}}$ & $51.50 \pm 1.10^{\mathrm{d}}$ & $2.55 \pm 0.14^{\mathrm{d}}$ \\
\hline $\begin{array}{l}\text { Group IV: } \\
\text { DN+ Lycopene }\end{array}$ & $0.38 \pm 0.02^{\mathrm{d}}$ & $9.40 \pm 0.32^{\mathrm{c}}$ & $74.70 \pm 1.59^{b}$ & $6.23 \pm 0.19^{b}$ \\
\hline
\end{tabular}

Data are presented as (Mean \pm S.E). $\quad$ S.E $=$ Standard error.

Mean values with different superscript letters in the same column are significantly different at $(\mathrm{P} \leq 0.05)$ 
Chronic hyperglycemia in the renal milieu stimulates the production of AGEs, the polyol pathway and activation of protein kinase C (PKC) which lead to increased ROS formation and oxidative stress (Pacher et al., 2005). Renal cells (glomerulus, tubules and fibroblasts) express NADPH oxidase and contribute to ROS formation in small amounts in the healthy state. In chronic hyperglycemia the dysfunctional renal cells can increase ROS generation which may enhance renal tissue injury (Shiose et al., 2001). In addition to structural and functional derangements the presence of excessive ROS in the renal milieu can promote dysregulation of renal medullary blood flow leading to renovascular hypertension that help in progression of diabetic nephropathy(Chabrashvili et al., 2002).

Presented findings showed that, a significant increase in serum glucose concentration was observed in STZ-induced diabetic nephropathy rats. These results are nearly similar to those reported by Akbarzadeh et al., (2007) who reported that, serum glucose levels was elevated three-fold in the diabetic animals group compared to normal who added that, Hyperglycemia, hypoinsulinemia, polyphagia, polyuria and polydipsia accompanied by weight loss were seen in adult rats within three days of STZtreatment which indicates irreversible destruction of Langerhans islets cells. Moreover, glucose metabolism through harmful alternate pathways such as via protein kinase $\mathrm{C}$ activation and advanced glycation end products formation contribute to development of DN (Ha, et al., 2008), and increased oxidative stress with subsequent alterations in celluar redox balance (Williamson et al ., 1993).
Administration of lycopene to $\mathrm{DN}$ rats significantly reduced elevated serum glucose level in STZ-induced diabetic nephropathy rats after 6 weeks from the onset of treatment with lycopene. These results are nearly similar to those recorded by Kuhad et al., (2008), Ali and Agha, (2009) as well as Aydin and Celik, (2012) who reported that, after treatment of diabetic nephropathy rats with lycopene serum glucose levels significantly decreased after week 3 and week 4 respectively when compared with control diabetic nephropathy group. This effect can be explained by the ability of lycopene to promote glycemic bioavailability in organs for body growth and reduction of the pathological symptoms (Ying et al., 2015).

The obtained results showed that, a significant increase in serum urea and creatinine concentrations were observed in STZ-induced diabetic nephropathy rats. These results are nearly similar to those reported by (Sayed, 2012) and (Akram Ahangarpour et al., 2016) who reported that, DN significantly increased serum urea and creatinine in the untreated diabetic nephropathy group in comparison with the non-diabetic nephropathy control group. Also, Lal et al., (2009) reported that, all diabetics have higher blood urea level, and has significantly higher uric acid level as compared to non-diabetic subjects due to continuous catabolism of amino acids high urea will be formed from urea cycle.

Urea is the one of the waste product excreted by the kidney and main end product of protein metabolism. An elevation of blood urea usually signifies decreased renal function (Sakami and Harrington, 1963). Moreover, (Ismail and Abd El-Gawad, 2010) demonstrated that, increase levels of serum 
uric acid, urea nitrogen and creatinine concentrations were observed in diabetic rats.Also, Bhatti et al., (2005) reported that, Urine albumin excretion increased by three fold with no change in plasma creatinine levels in the diabetic rats non-treated group.

Administration of lycopene to STZ induced diabetic nephropathy rats significantly decreased serum urea and creatinine concentrations. These results are nearly similar to those reported by (Wei et al., 2014) and (Dilek et al., 2016) who reported that, lycopene treatment prevented the development of diabetic nephropathy by remarkably decreasing creatinine and BUN in diabetic rats with less renal injury due to the increased elimination of blood creatinine and urea by the kidneys and reduced ptotein degradation. Also, Shams et al., (2015) reported that, treatment with lycopene for five weeks normalized the creatinine and BUN levels leading to improved GFR in diabetic rats.

The obtained results showed that, a significant decrease in kidney SOD activity was observed in STZ-induced diabetic nephropathy rats. These results are nearly similar to those reported by Daniel et al., (2015) and Kedziora-Kornatowska et al., (2000) who recorded that, reduced kidney activity of SOD three to six weeks after STZ administration compared to control group. Also, Mohora et al., (2006) reported that, increased level of MDA and low SOD activity are found in diabetes which confirmed the involvement of oxidative stress in renal injury induced in diabetic rats.

Treatment with lycopene to STZinduced diabetic nephropathy rats significantly increased kidney SOD activity. These results are nearly similar to those reported by Bukan et al., (2003) and Daniel et al., (2015) who reported that, lycopene treatment exerts antioxidant activity and protects the tissue from lipid peroxidation as well as kidney antioxidant enzymes (SOD, CAT and GPx) of diabetic animals were significantly decreased compared to normal control group. Also, Porrini et al., (2005) demonstrated that, consumption of tomato products which contain lycopene may decrease biomarkers level of oxidative stress in healthy subjects, smokers and type 2 diabetic patients.

$\mathrm{DN}$ is a serious and important microvascular complication that occurs frequently in patients with diabetes. The pathogenetic mechanisms for the microvascular complications may be associated with oxidative stress which is regarded as the major factor that couples hyperglycemia with vascular complications. Oxidative stress causes an increase of ROS which can attack at various target organ systems (Papaharalambus and Griendling, 2007). Lycopene possess antioxidant activity because of its open $\beta$ cycle structure. Moreover, lycopene can function as an antioxidant by several mechanisms, and one of the best documented mechanisms is through strong singlet oxygen quencher (Ojha et al., 2013). Another mechanism for the antioxidant activity of lycopene is reaction with free radicals (Krinsky, 1998). In addition to direct quenching of ROS and free radicals, lycopene can up-regulate the antioxidant response element and thereby stimulate the production of cellular enzymes such as SOD, CAT, GPx and quinone reductase that protect cells from ROS and other electrophilic molecules. For example, Ben-Dor et al., (2005) recorded that, lycopene up-regulates the antioxidant response element (ARE) in human liver cancer (HepG2) and breast cancer (MCF-7) cell line through the nuclear factor erythroid 2-related factor 2 (Nrf2) nuclear transcription pathway. Nrf2 is a critical transcription factor regulating the anti-oxidant genes such as GSH, SOD and CAT by binding to 
antioxidant response elements (Barcelos et al., 2016).

The obtained results showed that, a significant decrease in kidney reduced glutathione concentration was observed in STZ-induced diabetic nephropathy rats compared to control rats, similar results were recorded by Jagdish and Nehal, (2011) and Jagdish et al., (2010) who demonstrated that, renal ischemia/reperfusion $\mathrm{I} / \mathrm{R}$ group of diabetic rats showed significantly decreased enzymatic activity of SOD, CAT and GSH when compared with the sham control rats. Glutathione provide a first line of defense against ROS, as it can scavenge free radicals and reduce $\mathrm{H}_{2} \mathrm{O}_{2}$. The decreased concentration of GSH in kidney might be due to NADPH depletion or GSH consumption in the removal of peroxide (Gumieniczek, 2005). The ratio of reduced glutathione/oxidized glutathione is one of many cellular redox couples that directly contribute to redox status. Depletion of reduced GSH either by conjugation and removal from the cell or oxidation to GSSG could significantly affect the overall redox potential of the cell (Yadav et al., 1997). GSH-dependent enzymes provide a second line of defense as they primarily detoxify noxious by products generated by ROS and also help to prevent propagation free radicals (Gumieniczek, 2005). Alsaif, (2009) reported that, GSH/GSSG (Reduced glutathione and Oxidized glutathione) ratio were found to be lowest in the kidney of diabetic rats group. Some workers (Obrosova et al., 2003) reported that, the concentrations in the diabetic kidney were found to be significantly reduced, suggesting that the reduced GSH concentrations may play a role in the development of diabetic complications.

Treatment with lycopene to STZinduced diabetic nephropathy rats showed a significant increase in kidney reduced glutathione when compared with diabetic nephropathy non treated group. These results agree with the previous results obtained by Subhash and Agrawal, (2007) who reported the beneficial effect of tomato lycopene intake in decreasing oxidative stress in diabetes whose singlet oxygen quenching ability is twice as higher than that of $\beta$ carotene and ten times higher than that of alpha tocopherol (Di Mascio and Sies, 1989). Lycopene having a good free radical scavenging capacity because of its unique structure (high number of conjugated double bonds) might have quenched the superoxide and other free radical anions which are highly released in diabetes due to the abnormal metabolism. Lycopene thereby increasing the concentration of SOD, GSH-Px and GR which are the most important cytosolic enzymes involved in antioxidant activities also lycopene thereby reversing the disturbed balance to the antioxidant enzyme side thus it is responsible for decreased oxidative stress. In this study lycopene supplementation also increased the levels of reduced glutathione, the most important antioxidant metabolite that plays an important role in maintaining good levels of glutathione peroxidase activity which is the main enzyme involved in removing the $\mathrm{H} 2 \mathrm{O} 2$ generated from dismutation of superoxide anions by superoxide dismutase. Moreover, GSH is the co-factor of several reducing enzymes such as dehydroascorbate reductase and endoperoxide isomerase (Lenzi et al., 1994).

Presented findings showed that, a significant increase in kidney L-MDA concentration, a marker of lipid peroxidation in STZ-induced diabetic nephropathy rats in comparison with the control normal group. Lipid peroxidation is a marker of cellular oxidative damage initiated by ROS (Farber et al., 1990). These results are nearly similar to those reported by Bukan et al., (2003), Siddiqui et al., (2011) and Erejuwa, (2012) 
who recorded that, a significantly increased kidney L-MDA in experimentally induced diabetes in animals. This increase in the kidney L-MDA indicated enhanced lipid peroxidation which could cause injury to the cells. Increased levels of lipid peroxides in the plasma are usually considered to be the consequence of high production and liberation of tissue lipid peroxides into circulation due to pathological changes (Al-Faris et al., 2010). Hyperglycaemia leads to generation of free radicals due to auto-oxidation of glucose and glycosylation of proteins (Tirgar et al., 2010). And induces oxitative stress which becomes the chief factor that leads to diabetic complications (Shuklak et al., 2012). Abnormal elevated levels of free radicals and the simultaneous reduction of antioxidant defense can result in damage of cellular organelles and enzymes, increased lipid peroxidation and development of insulin resistance (Kumar et al., 2012). The elevated level of lipid peroxidation causes oxidative damage by increasing peroxy radicals and hydroxyl radicals (Singh et al., 2012), and is usually measured through the catabolite, malonaldehyde (MDA) in terms of TBARS as a marker of lipid peroxidation (KedzioraKornatowska et al., 2000). Also, increased lipid peroxide may be due to the increased glycation of protein in diabetes mellitus. The glycated protein might themselves act as a source of free radicals. There is a clear association between lipid peroxide and glucose concentration which may be also thought to play a role in increased lipid peroxidation in diabetes mellitus (Suryawanshi et al., 2006).

Oxidative stress is considered as an imbalance between oxidants and antioxidants. The accumulated ROS could interact with polyunsa- turated fatty acids leading to the formation of lipid peroxidation in kidney tissues and consequently result in damage or toxicity (Alarcon-Aguilar et al., 2010). It is widely acknowledged that oxidative stress is the major factor of diabetic complications including diabetic nephropathy (Rolo and Palmeira, 2006). ROS degrades membrane polyunsaturated fatty acids and produces 4hydroxylnonenal (4-HNE) and malondialdehyde (MDA) (Zhu et al., 2015). MDA is a highly unstable aldehyde which could induce oxidative stress by forming a covalent protein adduct which serves as a hallmark of oxidative stress in tissue injury (Chang et al., 2015).

In the present study, the decrease in kidney tissue L-MDA upon administration of lycopene to diabetic nephropathy rats is clearly demonstrated the antioxidant property of lycopene and its role is an efficient free radical scavenger (Palabiyik et al., 2013), because of its unique structure (high number of conjugated double bonds). It has the ability to quench the superoxide and other free radical anions (Bose and Agrawal, 2006). Also, from the above results it is proved that lycopene reduces the lipid peroxidation rate by acting as a good chain breaking antioxidant which reacts with peroxy radicals formed in propagation phase of lipid peroxidation to form carbon centered radical that reacts readily and reversibly with oxygen to form a new chain-carrying peroxyl radicals which are highly stable forms than ROS (Aggarwal et al., 2009).

Presented findings showed that, NF$\mathrm{kB}$ gene expression level in kidney of STZinduced diabetic nephropathy rats is significantly up-regulated compared to normal control group. Similarly, Iwamoto et al., (2001) who reported that, in STZ-induced diabetes, NF-kB was up-regulated in renal cortical tissue. Also, Lal et al., (2001) observed that, advanced glycation endproducts induced oxidative stress and upregulated NFkB in mesangial cells. 
Treatment with lycopene to STZinduced diabetic nephropathy rats caused a significant downregulation in kidney tissue $\mathrm{NF}-\kappa \mathrm{B}$ gene expression when compared with diabetic nephropathy non-treated group. These results are nearly similar to those reported by Shams et al., (2015) who showed that, lycopene significantly down regulated gene expressions of NF-kB and MMP-2 in diabetic nephropathy rats and lowered the inflammatory response markers such as TNF$\alpha$, IL-1, IL-6 and IFN- $\gamma$ by inhibiting the activation of AGE-RAGE signaling when compared with non-treated rats. Possible mechanisms for lycopene anti-inflammatory response may include the inhibition of synthesis and release of pro-inflammatory cytokines, synthesis and modulation of signal transduction pathways including that of the iNOS via its inhibitory effects on $N F-\kappa B$ (Palozza et al., 2010). Moreover, Feng et al., (2010) indicated that, the anti-inflammatory effects of lycopene depend on inhibition of NO and IL-6 production as well as suppression of $\mathrm{NF}-\kappa \mathrm{B}$ transcriptional activity and associated downstream pathways. The activation of NF-kB, monocyte chemoattractant protein-1 (MCP-1) and macrophage infiltration in the diabetic kidney were explored in a temporal manner. The active subunit of NF-kB p65 was elevated in the diabetic animals in association with increased MCP-1 gene expression and macrophage infiltration (Cha et al., 2005). The present study is consistent with these results, confirming that the anti-inflammatory activities of lycopene are mediated by down regulation of NF-kB gene expression resulting in reduced kidney tissue inflammation and tubulointerstitial nephritis.

\section{CONCLUSION:}

From the obtained results it could be concluded that, the experimental induction of diabetic nephropathy in male rats caused a significant increase in serum glucose, urea and creatinine concentrations as well as a significant increase in L-MDA level with a significant upregulation of NF-kB gene expression in kidney tissues. Also, there was a significant decrease in kidney tissue SOD activity and GSH level. however, lycopene treatment in STZ-induced diabetic nephropathy rats relieved all previous parameters towards its normal range so, these results confirm the strong antioxidant and anti-inflammatory effects of lycopene in STZinduced diabetic nephropathy.

\section{REFERRENCES:}

Abdel-Azeem, A.S.; Hegazy, A.M.; Ibrahim, K.S.; Farrag, A.R. and El-Sayed, E.M. (2013): Hepatoprotective, antioxidant, and ameliorative effects of ginger (Zingiber officinale Roscoe) and vitamin $\mathrm{E}$ in acetaminophen treated rats. Journal of Dietary Supplements; 10:195-209.

Aggarwal S, Singh K and Nagpal M. 2009. Studies on the effect of lycored supplementation (lycopene) on lipid peroxidation and reduced glutathione in pregnancy induced hypertensive patients. Biomed Res20:51-4.

Akbarzadeh,

A.;Norouzian,D.;Mehrabi,M.R.;Jams hidi,S.h. Farhangi, A.; Allah Verdi, A.;Mofidian,S.M. and Lame Rad,B. 2007. Induction of diabetes by streptozotocin in rats, Indian Journal of Clinical Biochemistry, 22 (2): 6064.

Akram R, Hassan G, Mahdi H, Farahanaz D, Tavakol H. S, and Farhad K. 2016. Tempol effects on diabetic nephropathy in male rats. J Renal Inj Prev. 5(2): 74-78.

Alarcon-Aguilar F., A. Fortis-Barrera, S. and Angeles-Mejia. 2010. Anti- 
inflammatory and antioxidant effects of a hypoglycemic fructan fraction from Psacalium peltatum (HBK) Cass. in streptozotocin-induced diabetes mice, J. Ethnopharmacol., 132(2), 400-407.

Al-Faris NA, Al-Sawadi AD, and Alokail MS, 2010. Effect of Samah seeds supplementation

(MesembryanthemumforsskaleiHochst ) on liver enzymes and lipid profiles of streptozotocin (STZ)-induced diabetic Wistar rats. Saudi Journal of Biological Sciences; 17:23-28.

Ali MM, and Agha FC, 2009. Amelioration of streptozotocin-induced diabetes mellitus, oxidative stress and dyslipidemia in rats by tomato extract lycopene. Scandinavian Journal of Clinical and Laboratory Investigation; 69(3): 371-379.

Alsaif, M.A. 2009. Beneficial Effects of Rutin and Vitamin C Coadministration in a Streptozotocin-Induced Diabetes Rat Model of Kidney Nephrotoxicity. Pakistan Journal of Nutrition 8 (6): 745-754.

Aydin M and Celik S,. 2012. Effects of lycopene on plasma glucose, insulin levels, oxidative stress, and body weights of streptozotocin-induced diabetic rats. Turkish Journal of Medical Sciences; 42 (Sup.2): 14061413.

Bagchi K and Puri S.1998. Free Radicals and Antioxidants in Health and Disease. Eastern Mediterranean Health J; 4:350-60.

Barcelos, R.P.; Bresciani, G.; RodriguezMiguelez, P.; Cuevas, M.J.; Soares, F.A.; Barbosa, N.V. and GonzalezGallego, J. 2016. Diclofenac pretreatment effects on the toll-like receptor 4/nuclear factor-kB-mediated inflammatory response to eccentric exercise in rat liver. Life Sciences, 148: 247-253.

Ben-Dor, A.; Steiner, M.; Gheber, L.; Danilenko, M.; Dubi, N.; Linnewiel, K.; Zick, A.; Sharoni, Y. and Levy, J. 2005. Carotenoids activate the antioxidant response element transcription system. Molecular Cancer Therapeutics, 4: 177-186.

Bhatti, F.; $\quad$ Mankhey, R.W.; $\quad$ Asico, L.; Quinn, M.T.; Welch, W.J. and Maric, C. 2005. Mechanisms of antioxidant and pro-oxidant effects of $\alpha$-lipoic acid in the diabetic and nondiabetic kidney. Kidney International, 67, 1371-1380.

Bose, K.S.C. and Agrawal, B.K. 2006. Effect of long term supplementation of tomatoes (cooked) on levels of antioxidant enzymes, lipid peroxidation rate, lipid profile and glycatedhaemoglobin in type 2 diabetes mellitus. West Indian Medical Journal, 55(4): 274-278.

Bukan, N.; Sancak, B.; Yavuz, O.; Koca, C.; Tutkun, F.; Ozcelikay, A. and Altan, N. 2003. lipid peroxidation and scavenining enzyme levels in the liver of streptozotocin - induced diabetic rats. vol 40, pp 447-450.

Cha DR, Kang YS, Han SY, Jee YH, Han $\mathrm{KH}$, Kim HE, Han JY and Kim YS. 2005. Role of aldosterone in diabetic nephropathy. Nephrology, 10, S37S39.

Chabrashvili T, Akahiro T, Maristela L. O, Chagriya K, Mark T. Q, Toshiro F, William J. W, Christopher S. W, 2002. Expression and cellular localization of classic NADPH 
oxidase subunits in the spontaneously hypertensive rat kidney. 39, 269-274.

Chang, F X. Luo, W. and Jiang 2015. Protective activity of salidroside against ethanol-induced gastric ulcer via the MAPK/NF-kappaB pathway in vivo and in vitro, Int. Immunopharmacol., 28(1), 604-615.

Chung, S.S.; Ho, E.C.; Lam, K.S. and Chung, S.K. 2003. Contribution of polyol pathway to diabetesinduced oxidative stress, J. Am. Soc. Nephrol., 14, S233-S236.

Daniel Eze Ejike, Aliyu Mohammed, Yusuf Tanko and Abubakar Ahmed 2015. Effects of lycopene on kidney antioxidant enzyme activities and functions in streptozotocin-induced diabetic Wistar rats. Cell Biology; 3(1): 1-13.

Di Mascio P Kaiser S, Sies H. 1989. Lycopene as a most effectivebiological carotenoid singlet oxygen quencher. Archives of Biochemistry and Biophysics; 274: 532-8.

Dilek Pandir, Betul Unal, Hatice Bas. 2016. Lycopene Protects the Diabetic Rat Kidney Against Oxidative Stressmediated Oxidative Damage Induced by Furan. Vol. 59: e16150794.

Erejuwa OO, 2012. Oxidative Stress in diabetes mellitus: is there arole for hypoglycaemic drugs and/or antioxidants? Oxidative stress and diseases, Volodymyr I. Lushchak and Dmytro V.Gospodaryov (Ed.), ISBN: 978-953-51-0552-7; InTech

Ergüder, B.; Avci, A.; Devrim, E. and Durak, I. (2007): Effects of cooking techniques on antioxidant enzyme activities of some fruits and vegetables. Turk J Med Sci; 37(3):151-156.

Farber, J.L.; Kyle, M.E. and Coleman, J.B. 1990. Mechanisms of cell injury by activated oxygen species. Lab Invest 62: 670-679.

Feng, D.; Ling, W.H. and Duan, R.D. 2010. Lycopene suppresses LPS induced NO and IL- 6 production by inhibiting the activation of ERK, p38MAPK, and NF-kappa B in macrophages. Inflammation Research 59(2): 115121.

Gallou, G.; Ruelland, A.; Campion, L. Maugendre; D.; Le Moullec, N.; Legras, B.; Allannic, H. and Cloarec, L. 1994. Increase in thiobarbituric acid-reactive substances and vascular complications in type 2 diabetes mellitus. Diabetes Metab, 20:258-264.

Gavin, J.R.; Alberti, K.J.; Davidson, M.B.; DeFronzon, R.A.; Drash, A. ;Gabbe, S.G.; Genuth, S.; Harris, M.I.; Kahn, R.; Keen, H.; Knowler, W.C.; Lebovitz, H.; Maclaren, N.K.; Palmer, J.P.; Raskin, P.; Rizza, R.A. and Stern, M.P. 1997. Report of the expert comitte on the diagnosis and classification of Diabetes Mellitus. Diabetes Care. 20: 1183-1197.

Gumieniczek, A., 2005. Effects of repaglinide on oxidative stress in tissues of diabetic rabbits. Diab.Res. Clin.Pract., 68: 89-95.

Ha H, Hwang IA, Park JH and Lee Hb. 2008. role of reactive oxygen species in the pathogenesis of diabetic nephropathy. Diabetes Res Clin Pract, 13:S42-S50.

Haidara MA, Mikhailidisc DP and Rateba MA. 2008. Evaluation of the effect of oxidative stress and vitamin $\mathrm{E}$ 
supplementation on renal function in rats with streptozotocin-induced type 1 diabetes. $J$ Diabetes Complications.

Huang, T.H.; Peng, G.; Kota, B.P.; Li, Q.G.; Yamahara, J.; Roufogalis, B.D. and Li, Y. 2005. Anti-diabetic action of Punica granatum flower extract: activation of PPAR- $\mathrm{Y}$ and identification of active component. Toxical. Pharm., 207: 160 - 169.

Ismail, R.S. and Abd El-Gawad, S.H. 2010. potential Effect of Egyptian Anna Apple Pomace ( Malus domestica , Rosaceae ) supplementation on kidney function, Liver function and lipid profile of diabetic rats .World Journal of Dairy \& Food Science ; 5(1):5866.

Iwamoto M, Mizuiri S and Tanimoto H. 2001. Nuclear factor-kB activation in streptozotocin induced diabetic rat's kidneys. J Am Soc Nephrol; 12: 838a.

Jagdish, K. and Nehal, S. 2011. Comparison effect of Pioglitazone and Glimepiride alone on renal function marker in experimentally induced renal damage in diabetic rats. Journal of Applied Pharmaceutical Science 01 (03); 7276.

Jagdish, K.; Mehul, S. and Nehal, S. 2010. Glimepiride reduces on experimentally induced ischemia/reperfusion in diabetic rats. Volume: I: Issue-2,276-285.

Jamshidzadeh, A.; Baghban, M.; Azarpira, N.; Bardbori, A. M. and Niknahad, $\mathrm{H}$. 2008. Effects of tomato extract on oxidative stress induced toxicity in different organs of rats. Food Chem. Toxicol., 46 (12). 3612-3615.

Kakadiya, J.; Shah, M. and Shah, N. 2010. Glimepiride reduces on experimentally induced is chemical reperfusion in diabetic rats. IJABPT, 1:276-285.

Kakkar, P., Das, B., Viswanathan, P.N. 1984. A modified spectrophotometric assay of superoxide dismutase. Indian J. Biochem Biophys 21, 130-132.

Kaneto, H.; Fujii, J.; Kamada, T. and Taniguchi, N. 1995. Apoptotic cell death triggered by nitric oxide in pancreatic beta-cells. Diabetes. 44: 733-738.

Kedziora-Kornatowska KZ, Luciak M, and Paszkowski J. 2000. Lipid peroxidation and activities of antioxidant enzymes in the diabetic kidney: Effect of treatment with angiotensin convertase inhibitors. International Union of Biochemistry and Molecular Biology Life; 49: 303307.

Kim, G.Y.; Kim, J.H.; Ahn, S.C.; Lee, H.J.; Moon, D.O.; Lee, C.M. and Park, Y.M. 2004. Lycopene suppresses the lipopolysaccharide- induced phenotypic and functional maturation of murine dendritic cells through inhibition of mitogen-activated protein kinases and nuclear factorkappa B. Immunology, 113: 203211.

Krinsky, N.I. 1998. The antioxidant and biological properties of the carotenoids. Annual of the New York Academy of Sciences, 854: 443-447.

Kuhad, A.; Sharma, S. and Chopra, K. 2008. Lycopene attenuates thermal hyperalzesia in a diabetic mouse model of neuropathic pain. Eur. J. Pain. 12: 624-632.

Kumar R, Kar B, Dolai N, Bala A, and Haldar PK, 2012. Evaluation of antihyperglycemic and antioxidant 
properties of Streblusasper- Lour against streptozotocin-induced diabetes in rats. Asian Pacific Journal of Tropical Disease; 2(2): 139-143.

Kumar, G.; Murugesan, A.G. and Rajasekara P, M. 2006. Effect of Helicteres isora bark extract on blood glucose and hepatic enzymes in experimental diabetes. Indian J. Exp. Biol. 22(3): 211-225.

Lal M, Brismar H, Eklof AC and Aperia A. 2001 Advanced glycation end products induce oxidative stress and activate NF-kB, PKCb1, and TGF-b1 in mesangial cells. $\mathrm{J}$ Am Soc Nephrol;12: 840a.

Lal, S.S.; Suk la, Y.; Singh, A.; Andriyas, E.A. and Lall, A.M. 2009. Hyperuricemia, High Serum Urea and Hypoproteinemia are the Risk Factor for Diabetes. Asian Journal of Medical Sciences 1(2): 33-34.

Lenzi A, Picardo M, Gandini L, Lombardo F and Terminali O.1994. Glutathione treatment of dyspermia: effect on lipoperoxidation process. Human Reproduction; 9(11): 2044-2050.

Livak, K.J. and Schmittgen, T.D. 2001. Analysis of relative gene expression data using real-time quantitative PCR and the $2^{-\Delta \Delta C}$ Method. Methods 25(4), 402-408.

Mesbah, L., Soraya, B., Narimane, S. and Jean, P.F. 2004. protective effect of flavonides against the toxicity of vinblastine cyclophosphamide and paracetamol by inhibition of lipid peroxydation and increase of liver glutathione. Haematol 7 (1), 59-67.

Mogensen, C. E., Christensen, C. K. and vittinghus, E. 1983. The stages in diabetic renal disease. With emphasis on the stage of incipient diabetic nephropathy. Diabetes 32 (Suppl. 2), 64-78.

Mohora M, Vîrgolici B, Paveliu F, Lixandru D, Muscurel C and Greabu M.2006. Free radical activity in obese patients with type 2 diabetes mellitus. Rom J Intern Med; 44: 69-78.

Obrosova, I.G.; Fathallah, L.; Liu, E. and Nourooz Zadeh, J. 2003. Early oxidative stress in the diabetic kidney: effect of DL-alpha-lipoic acid. Free Radic. Biol. Med., 15; 34(2): 186-195.

Ojha, S., Goyal, S.; Sharma, C.; Arora, S.; Kumari, S. and Arya, D.S. 2013. Cardioprotective effect of lycopene against isoproterenol-induced myocardial infarction in rats. Human and Experimental Toxicology; 32: 492-503.

Pacher, P., Obrosova, I. G., Mabley, J. G. and Szabó, C.2005. Role of nitrosative stress and peroxynitrite in the pathogenesis of diabetic complications. Emerging new therapeutical strategies. Curr.Med. Chem. 12, 267-275.

Paglia DE and Valentine WN.1967. Studies on the quantitative and qualitative characterization of erythrocyte glutathione peroxidase. $\mathrm{J} \mathrm{Lab} \mathrm{Clin}$ Med.70 (1) : 158-69.

Palabiyik, S.S.; Erkekoglu, P.; Zeybek, N.D.; Kizilgun, M.; Baydar, D.E.; Sahin, G. and Giray, B.K. 2013. Protective effect of lycopene against ochratoxin A induced renal oxidative stress and apoptosis in rats. Experimental and Toxicologic Pathology, 65: 853-861.

Palozza, P.; Parrone, N.; Catalano, A. and Simone, R. 2010. Tomato lycopene 
and inflammatory cascade: Basic interactions and clinical implications. Current Medicinal Chemistry; 17(23):2547-2563.

Papaharalambus CA and Griendling KK. 2007. Basic mechanisms of oxidative stress and reactive oxygen species in cardiovascular injury. Trends Cardiovasc Med; 17: 48-54.

Porrini M, Riso P, Brusamolino A, Berti C, Guarnieri S and Visioli F. 2005. Daily intake of a formulated tomato drink affects carotenoid plasma and lymphocyte concentrations and improves cellular antioxidant protection. Br J Nutr; 93: 93-9.

Ramanathan, M.; Jaiswal, A.K. and Bhattacharya, S.K. 1999. Superoxide dismutase, catalase jand glutahiones peroxidase activities in the brain of streptozotocin induced diabetic rats. Indian. J.Exp.Biol.; 37: 182-183.

Riso, P.; Visioli, F.; Grande, S.; Guarnieri, S.; Gardana, C.; Simonetti, P. and Porrini, M. 2006. Effect of a tomatobased drink on markers of inflammation, immunomodulation, and oxidative stress. J. Agric Food Chem., 54:2563-2566.

Rolo A. P. and C. M. Palmeira, 2006. Diabetes and mitochondrial function: role of hyperglycemia and oxidative stress, Toxicol. Appl. Pharmacol., 212(2), 167-178.

Sakami, W. and Harrington, H. 1963. Amino acid metabolism, Ann. Rev. Biochem., 32: 355-398.

Sayed A.A. 2012. Thymoquinone and proanthocyanidin attenuation of diabetic nephropathy in rats.Eur Rev Med Pharmacol Sci, 16:808-815.
Shams T, Khalid Z. Al-Shali and Saheem A. 2015. Lycopene powers the inhibition of glycation-induced diabetic nephropathy: A novel approach to halt the AGE-RAGE axis menace. International Union of Biochemistry and Molecular Biology. DOI 10.1002/biof.1238.

$\underline{\text { Shiose }}$ A, Junya $\mathrm{K}, \underline{\text { Kazuhiko T, Momoki }}$ $\underline{\mathrm{H}}, \underline{\text { Hideki } \quad \mathrm{H}}, \quad$ Seiji N,$\underline{\text { Masahira }}$

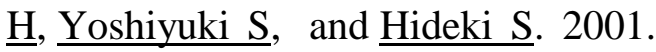
A novel superoxide-producing $\mathrm{NAD}(\mathrm{P}) \mathrm{H}$ oxidase in kidney. J. Biol. Chem. 276, 1417-1423.

ShuklaK, Dikshit P, Tyagi MK, Shukla R, and Gambhir JK, 2012.Ameliorative effect of Withaniacoagulans on dyslipidaemia and oxidative stress in nicotinamide-streptozotocin induced diabetes mellitus. Food and Chemical Toxicology, 50: 3595-3599.

Siddiqui $\mathrm{MH}$, Al-Whaibi $\mathrm{MH}$, and Basalah MO, 2011. Role of nitricoxide in tolerance ofplants to abiotic stress. Protoplasma; 248: 447-455.

Singh U, Singh S, and Kochhar A, (2012). Therapeutic potential of antidiabetic nutraceuticals. Phytopharmacology; 2(2):144-169.

Subhash. C. Bose K. and Agrawal. B.K. 2007. Effect of short term supplementation of tomatoes on antioxidant enzymes and lipid peroxidation in type-II diabetes. Indian Journal of Clinical Biochemistry, 22 (1) 95-98.

Suryawanshi, N.P.; Bhutey, A.K.; Nagdeote, A.N.; Jadhav, A.A. and Manoorkar, G.S. 2006. Study of lipid peroxide and lipid profile in diabetes mellitus. Indian Journal of Clinical Biochemistry, 21 (1) 126-130. 
Tietz, N.W. 1986. Textbook of clinical chemistery. WB saunders, Philadelphia, pp 1271-1281.

Tietz, N.W. ED. 1990. Clinical guide to laboratory tests. 2 ND ED. Philadelphia: WB Saunders; 566.

Tietz, N.W. ed. 1995. Clinical guide to laboratory tests. 3rd ed. Philadeiphia.WB Saunders; 268-273.

Tirgar P, Jadav P, Sheth D, Desai T, Tirgar PR, Jadav PD, and Sheth MDB, 2010. Therapeutic role of anti-oxidant properties of Emblicaofficinalis(amla) in streptozotocin induced type 1 diabetic rats. Pharmacology online; 1:728-743.

Wei L, Guoguang W, Xiaohua L, Yuxin J, Lei X, Xue Z. 2014. Lycopene ameliorates renal function in rats with streptozotocin-induced diabetes. Int J Clin Exp Pathol;7(8):5008-5015.

Wertz, K.; Siler, U. and Goralczyk, R. 2004. Lycopene: modes of action to promote prostate health. Arch. Biochem. Biophysi., 430: 127-134.

Williamson, J.R.; Chang, K.; Kilo, C. and Tilton, R.G. 1993. Hyperglycemic pseudohypoxia land diabetic complications. Diabetes. 42: 801813.

Yadav, P.; Sarkar, S. and Bhatnagar, D. 1997. Lipid peroxidation and antioxidant enzymes in erythrocytes and tissues in aged diabetic rats. Ind J Exp Biol 35: 389-392.

Ying Guo, Yihui Liu and Yuxia Wang. 2015. Beneficial effect of lycopene on antidiabetic nephropathy through diminishing inflammatory

Zhu, T L. Wei, X. and Chang, 2015. Effects of Salidroside on M [pp'yocardial Injury In Vivo In Vitro via Regulation of Nox/ NF-kappaB/AP1 Pathway, Inflammation, 38(4), 1589-1598. 